\title{
CRI MSONpublishers
}

http://www.crimsonpublishers.com

\section{Opinion}

ISSN 2578-0042

\section{The Interdisciplinarity in Research about Time}

\author{
Patrice F Dassonvillle* \\ Author of the Invention of Time and Space: Origins, Definitions, Nature, Properties, France
}

*Corresponding author: Patrice F Dassonvillle, Author of the Invention of Time and Space: Origins, Definitions, Nature, Properties, France

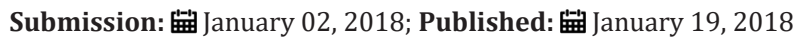

\section{Opinion}

The bishop Aurelius [1] complained that time was familiar to him, but totaly elusive as soon as he attempted to explain it. In The Paradise (XX), Dante [2] deplored that we know the name of things whereas we don't know their meaning, until others explain it.

Milestones of theorization of time are punctuated by crosscutting approaches coming from various fields of knowledge: interdisciplinarity plays a major role in progression of the methodology and its consequences in identifying the concepts of time.

\section{Epistemology}

One must beware of everyday language and metaphors. Definitions should get rid of formal defects, etc.:

Ex: The usual aphorism time flies implies that time has a speed, which is expressed in relation to time; but the speed of time related to time is nonsense; therefore time flies is a sophism.

Ex: In 1967, the Conférence Générale des Poids et Mesures (CGPM) decided: « The second is the duration of 9, 192, 631, 770 periods of the radiation corresponding to the transition between the two hyperfine levels of the ground state of the cesium 133 atom».

It turns out that the "period » is " the duration of a cycle »; therefore «the duration of a period » (the duration of duration of a cycle) is a pleonasm.

Ex: In 1983, the CGPM decided to agree on the exact value of the speed of light: $c=299,792,458 \mathrm{~m} / \mathrm{s}$. The same Conference has proposed a new definition of the meter: « The meter is the distance travelled in the vacuum by the light during $1 / 299,792,458^{\text {th }}$ second $»$.

Defining « $\mathrm{c} »$ in relation to the meter, and in the wake, defining the meter in relation to « $\mathrm{c}$ », is a truism. In addition, it makes the meter depend on the second; such that space is de jure alienated to time...

\section{Epigraphy and Linguistic}

Deciphering of hieroglyphs and cuneiform writings allowed for uncovering first traces of temporalite (Figure 1), although translations are not always reliable:

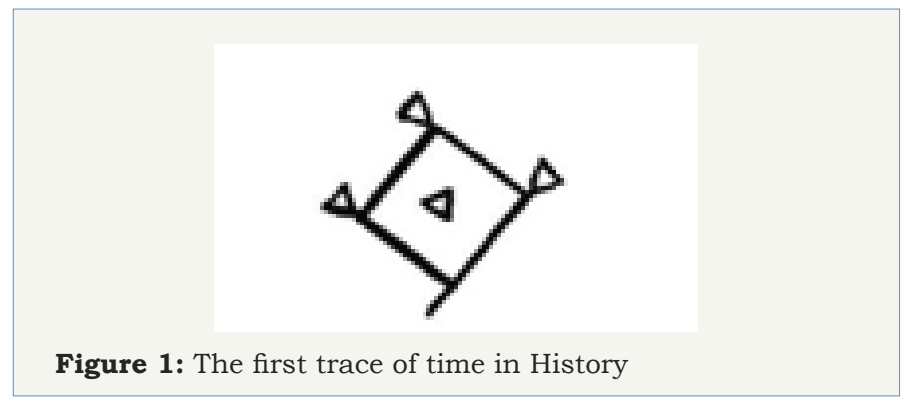

Ex: In the Vulgata Venice (1551): Et fuerût cuncti dies Adam quoad vixit, nongenti anni et triginta anni (Genesis, V,5), which is translated to: All the time that Adam lived was therefore nine hundred and thirty years (Wogue [3]) : «all the days » is translated to « all the time »; it's an anachronism because « time » is unknown by the oral tradition.

Ex: The vizier Ptahotep begged his king Isesi (c.2400 BC) to discharge him of his funtions: he complained of the « long duration of life » (Lalouette [4]), instead of « the many years of life »; the concept of duration was unknown at the time [5].

\section{Archeology}

Archeologists' investigations lead to discovery of major information. An awesome example is given by a clay tablet from Sumer (2800-2500 BC) which is engraved with a crucial cuneiform sign (Figure 1); indeed, this sign means « lunar month » (Conteneau) [6]. The analyze of Sumerians' approach shows the consistent way for wording definitions.

\section{Architecture}

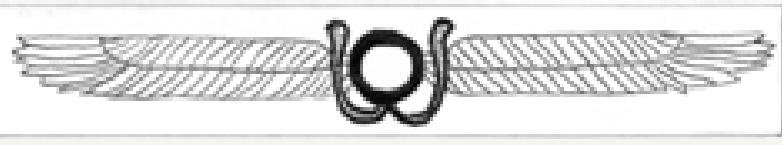

Figure 2: A widespread precursor of time and space.

In Persia, in Mesopotamia in Phoenicia, in Egypt, many ancient monuments are engraved with signs of temporality.

Ex: As far back as the 3rd millennium, the Sun and the divine principle were related in a sacred conception of temporality and spatiality. This Egyptian hieroglyph (Figure 2) symbolizes the solar 
God cycle Re. Spread wings of Goddess Nephthys symbolize Sun's path, with the alternance of days and nights, and with the rebirth after death: hence the idea of eternity.

\section{Anthropology and Ethnography}

The Dogon in Northeastern Mali still unthinkingly use the sigi as a kind of unit which corresponds to 60 low waters of Niger. The Sigi is also a ceremony which goes on for eight years and which provides a way for genealogists to preserve their history in their tremendous memory.

The absence of temporality (achrony) is still identified in some contemporary cultures, such as Penan of Borneo Island (Greg): it proves that time is neither an intuition, which was asserted by Kant, nor a fundamental category of thought, which was supposed by Aristotle and Kant (Cuvilier).

\section{Geography}

Many precusors and prototypes of time (Figure 2) are identified in China, in Egypt, in Persia, in Phoenicia, in the Hittite empire, in Mesopotamia, in the Mayan empire, in Africa, etc. The concept of time is polygenic, knowing that many current cultures don't know it.

\section{Mathematics}

Mathematics doesn't exist in nature; they are a prodigious operating mode of thought facing complexity of nature. Physics would be nothing without mathematical concepts which open the way to mathematical modelizations of physical phenomena.

\section{The \\ CLOCK The parameter of reference

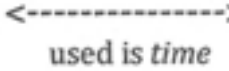 \\ PHENOMENON}

Figure 3: Evaluation of a phenomenon with a clock.

Time has no physical properties, but it has mathematical properties of a great theoretical interest. Time is an intermediate parameter between something we know and something we don't know (Figure 3). Time is also an intermediate parameter in comparing two systems A and B (Figure 4).

\begin{tabular}{|c|c|}
\hline & Parameters \\
SYSTEM A & of reference \\
Figure 4: Comparison between two systems.
\end{tabular}

\section{Physics}

Time has no physical properties. It's not a state variable. Therefore, no experience can be done on it; a measurement of a duration, which is an experience, is impossible. For example, the relativistic experiences are not operated on the concept of time, but on the states of relativistic systems, which are used for defining time.

\section{Philosophy}

The countless questionings of philosophy are highly fruitful. The failure of the solutions suggested by contemporary philosophy such as Bergson [7] and Heidegger [8], emphasizes the complexity of the issue. Perhaps instead of trying for their part, philosophers should have insisted on scientists to identify the nature of time.

\section{High Technology and Advanced Techniques}

They play a leading role in the design of ultra-precise measuring devices. We keep in mind that time is defined in relation to the change of state of any system.

\section{Psychology}

The « primary effect of field » was introduced by the Swiss psychologist Jean piaget, in order to describe and explain effects produced on the mind by certain phenomena. Ex: time passing at different rates, depending on whether the activity performed is enjoyable or not (heterochrony).

We have introduced two extensions of this concept:

a. The « technical effect of field »

Ex: The flow of a river brings to mind the irreversible passage of time.

b. The « effect of field model »

Ex: the equation, distance $=$ speed $\mathrm{x}$ time, $(\mathrm{d}=\mathrm{v} . \mathrm{t})$, is suggesting that time plays an active role, which is wrong.

\section{Medicine and Biology}

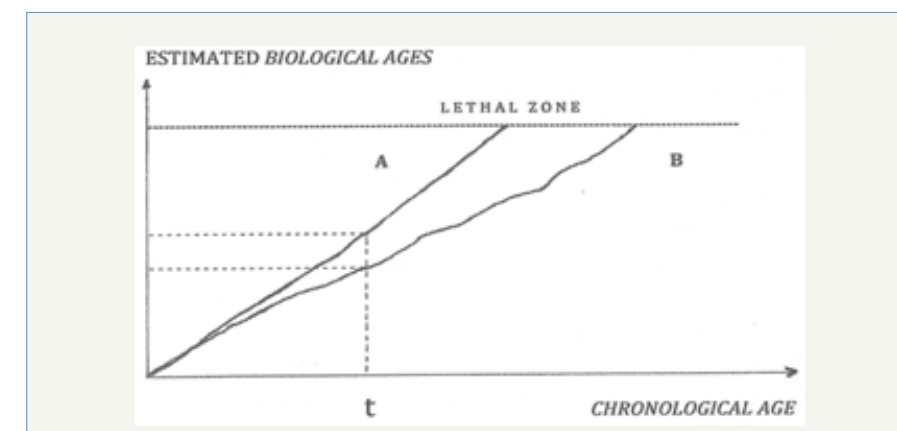

Figure 5: Biological age of two individuals A and B same chronological age.

Medicine makes a difference between « chronological age » and «biological age »

Chronological age: Indicates the number of years since birth. The information is very poor because it contains no data about the individual. Therefore, chronological age is not a state variable.

Biological age: It is apparent age due to physical and mental health condition. The information is very rich because it includes an indefinite number of data concerning the individual: these data are « state variables » in which time is not involved.

Time is not implied in etiology of aging. Aging is caused by genetic inheritance, environment including way of lifef, and potentiation of both. By looking at the stage of development of 
fly larvae collected on a cadaver, police forensics can accurately determine the date of death. These datings are done without using a clock.

\section{History and Literature}

The investigation through ancient litterature shows how precursors of temporality emerged.

We find the first units of speed in Herodotus [9] (Book I, 203; Book II, 19, 31) : " walk in a day », « navigation in a day », « navigation in a month »; in Plutarch [10] : « Navigation in a day » (Life of Timoleon, 25,5).

We can observe the erratic value of the year: Plutarch writes that in Egypt, the year had one month first, and then four months. He writes that before Caesar in Rome, the relation between year and month was very confused (Life of Caesar,59,2); the year had ten months until the reign of Numa (c.715-c.672) (Life of Numa, 19, 1). The Consul Ausonius was the first in Rome who associated the regular coming of the seasons with Annus (year). (Conteneau : p. 553).

The Calends where the first day of the lunar month in Greece: Plutarch points out that among some barbarians (people who did not speak Greek), the year had three months; for Arcadians of Peloponnese the year had four months, and that of Acarnanes had six months (Life of Numa, 18,6). Plutarch reports that Philippides affirm that Stratocles reduced the year to one month. (Life of Demetrius, 26,5).

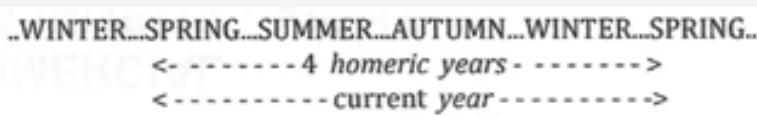

Figure 6: The Homeric year compared to our current Year.

In the «Odyssey», the Greek poet Homer (8th century BC) writes this incredible verse: when the fourth year came, when the seasons started again. (Song II). In clear, the return of the seasons took place every four years. (Figure 6): the homeric year had three months. In Greece during the 8th century BC, the year had three months.

The erratic values of the year would certainly explain the extravagant age of the biblical Patriachs $[11,12]$.

\section{Plastic Arts}

Marcel Duchamp (1887-1968) has initiated the kinetic cubism with « Nude descending a staircase » painted in 1912 (Philadelphia Museum of Art): time and space are rendered through an amazing representation of the movement.

Art painting also gives examples of anachronisms:

Ex: Tradition suggests that Moses might have lived during the 13th century BC. Rembrandt (1606-1669) represents the Tables of the Law with Hebrew letters although consonantal Hebrew writing emerged during the $9^{\text {th }}$ century BC. José Ribera (15911652) represents the Tables of the Law with Greek letters although consonantal Greek writing emerged during the $11^{\text {th }}$ century BC. The Tables might have been engraved either with Egyptian hieroglyphic writing (c.3300 BC), or with Egyptian hieratic writing (c.2400 BC) in accordance with the birth place of Moses, or with Sumerian pictographic writing (c.2300 BC), or Ugaritic cuneiform writing $\left(14^{\text {th }}-13^{\text {th }} B C\right)$.

Ex: Representations of Adam and Eve with a belly button by Masaccio (1427), Albrecht Dürer (1504), Titian (1550), Cranach the Elder (c.1513), are other examples of anachronisms.

\section{Religions}

Time is a sensitive issue because it was invented by Gods, in order to master their creations with the help of aging and death. Gods were and they still are supra-temporal: they are not affected by time. Many religions invented «start of times » and « end of times ». Monarchs thought they were divine and they believed in eternal life for them. The concepts of " life post mortem », " eternal life » and « eternity » have been introduced by religions, mainly in Egypt, and in Mesopotomia with the Gilgamesh Epic (Sumer, c. 2700 BC).

These examples illustrate the effectiveness of using crosssectionnal data from various disciplines. Of course the exercise is facilitated by the fact that the concept of «time » is used almost worldwide.

\section{References}

1. Augustin A (354-430) born in Hippone, a former Cartaginian colony : Confessions.

2. Dante A (1265-1321): The Divine Comedy, The Paradise XX (Thill Éditeur - Paris).

3. Wogue L,Thora (Société Encyclopédique Française - Paris 1966).

4. Lalouette C: Au Royaume d'Égypte - (Fayard - Paris 1991).

5. www.bipm.org

6. Conteneau G : La Civilisation d'Assur et de Babylone - (Payot - Paris 1937).

7. Bergson H (1859-1941): L'Évolution Créatrice (1907)-(P.U.F. - Paris 1947).

8. Heidegger M (1889-1976): Sein und Zeit-1927 (from E. Martineau).

9. Herodotus (484-425): The Histories (from A. Barguet, Gallimard - Paris 1964).

10. Plutarch (c. 46 - c. 126) : Parallel Lives (Robert Laffont - Paris 2001)

11. Cuvillier A: Petit Vocabulaire de la Langue Philosophique - (Armand Colin - Paris1955).

12. Greg A, McKenzie I: Les derniers nomades (TV - Arte - France November 2008) 